Neutron and Gamma Fluxes and dpa Rates for HFIR Vessel Beltline Region (Present and Upgrade Designs) Supplement 1

E. D. Blakeman 


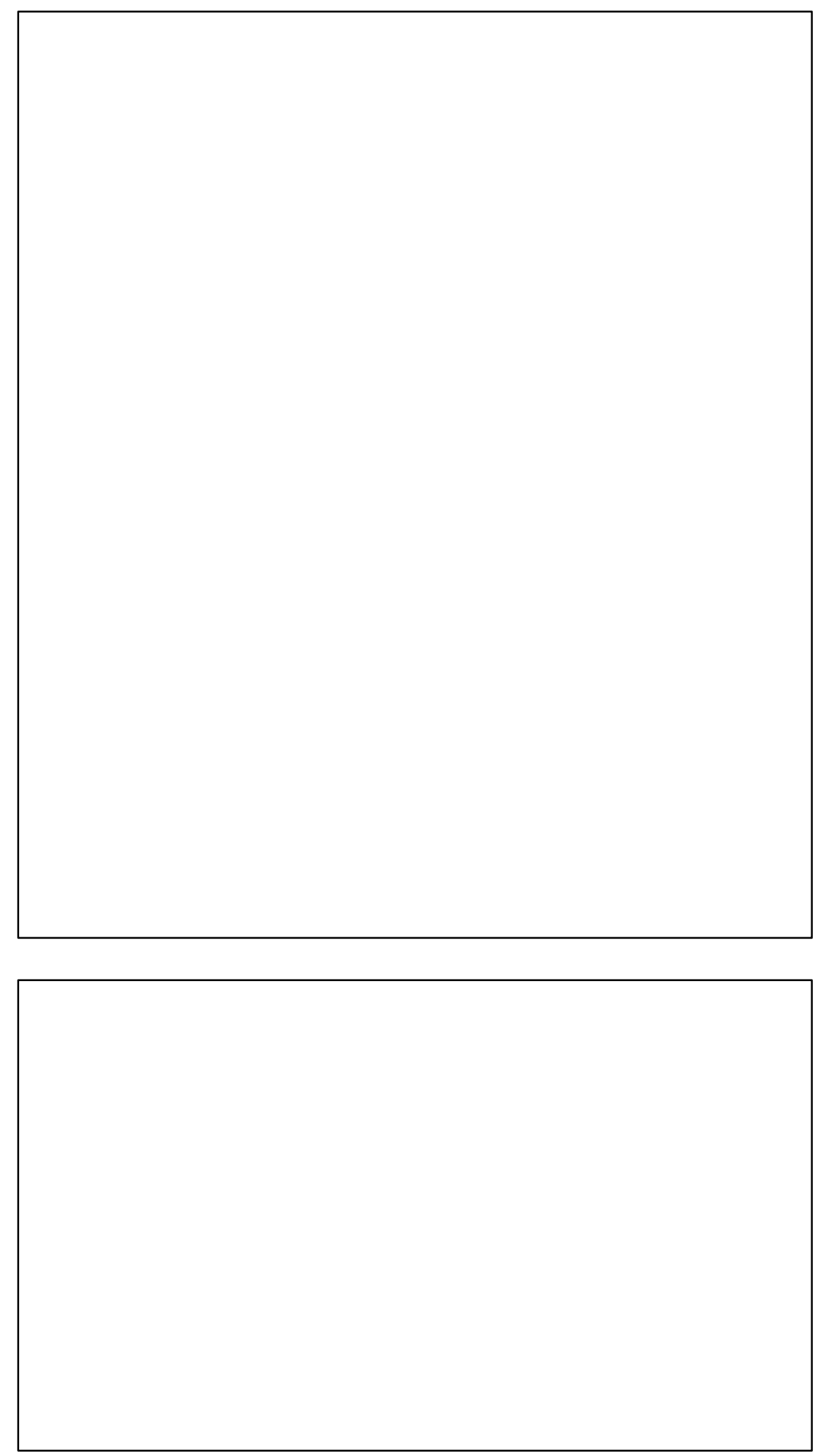


ORNL/TM-13693/S1

Computational Physics and Engineering Division

\title{
Neutron and Gamma Fluxes and dpa Rates for HFIR Vessel Beltline Region (Present and Upgrade Designs) Supplement 1
}

E. D. Blakeman

Date published: December 2000

\author{
Prepared by the \\ OAK RIDGE NATIONAL LABORATORY \\ Oak Ridge, TN 37831-6363 \\ Managed by \\ UT-BATTELLE, LLC, \\ for the \\ U.S. DEPARTMENT OF ENERGY \\ under contract DE-AC05-00OR22725
}





\section{CONTENTS}

Page

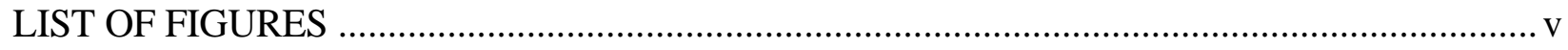

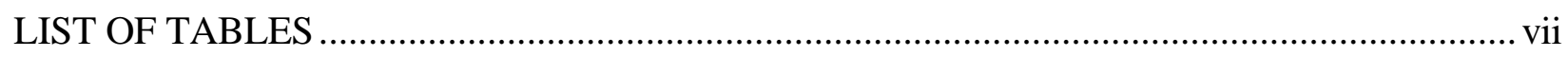

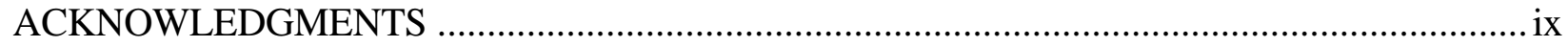

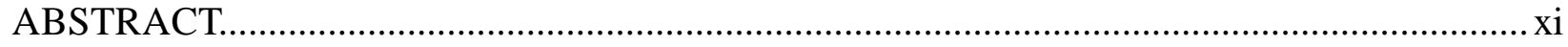

1. INTRODUCTION

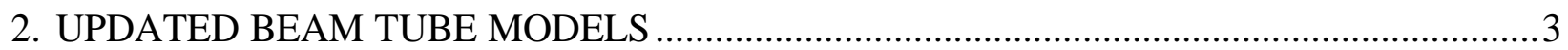

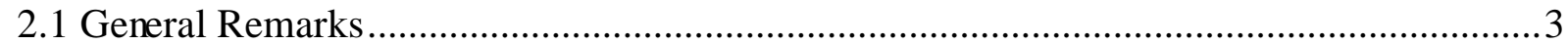

2.2 Updated Model for HB-1 (HB-4, Present Design) ........................................................... 9

2.3 Updated Model for HB-2 New Design........................................................................

2.4 Updated Model for HB-3 Present Design......................................................................

2.5 Updated Model for HB-4 New Design.............................................................................

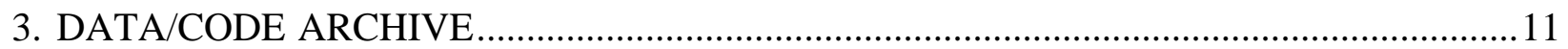

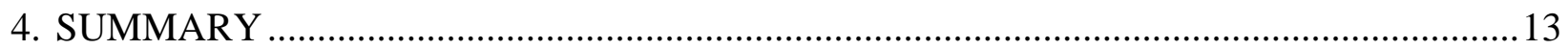

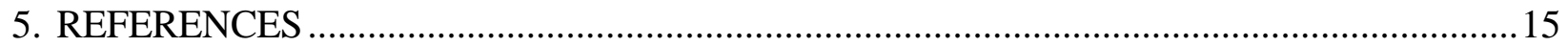

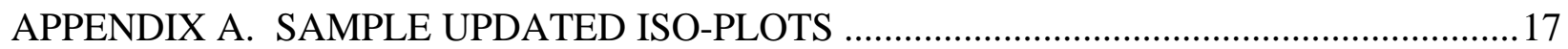

APPENDIX B. GUIDE TO CALCULATION MODELS FOR HFIR BEAM TUBES AND DATA ARCHIVAL STORAGE, SUPPLEMENTAL INFORMATION ...................................25 



\section{LIST OF FIGURES}

Figure $\quad$ Page

1. Geometry/material model for HB-1 and HB-4 (present design; HB-4 shown;

HB-1 is mirror image) with specimen mount included.

2. Geometry/material model for HB-2 (present design) ....................................................5

3. Geometry/material model for HB-2 (new design) with specimen mount included................6

4. Geometry/material model for HB-3 with specimen mount included. ................................ 7

5. Geometry/material model for HB-4 (new design) with specimen mount included................8

6. Detail of model implementation of specimen mount for HB-2 (new design).....................10

A1. Total (neutron + gamma) iso-dpa rate (displacements/atom/s) for HB-1 and HB-4 (present design; HB-4 shown; HB-1 is mirror image) with specimen mount included. ........20

A2. Total (neutron + gamma) iso-dpa rate (displacements/atom/s) for HB-2 (new design) with specimen mount included.

A3. Total (neutron + gamma) iso-dpa rate (displacements/atom/s) for HB-3 with specimen mount included.

A4. Total (neutron + gamma) iso-dpa rate (displacements/atom/s) for HB-4 (new design) with specimen mount included. 



\section{LIST OF TABLES}

Table $\quad$ Page

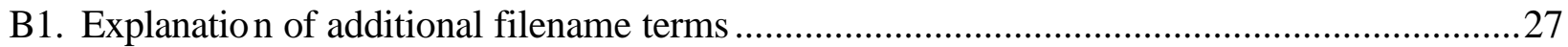

B2. List of additional DORT/TORT code inputs by beam tube design...................................22 



\section{ACKNOWLEDGMENTS}

The author extends his appreciation to R. D. Cheverton for his technical advice and support. The author wishes also to thank M. R. Whittenbarger and E. A. Hutson for their help in preparing the manuscript. 



\begin{abstract}
Supplemental analyses are described that include the addition of surveillance specimen mounts to discrete ordinates models of HFIR beam tubes. These models have been used to calculate the changes in the displacements/atom/s (dpa rate) in the reactor vessel wall that result from design changes in the HB-2 and HB-4 beam tubes. The dpa rate is related to the embrittlement of the vessel wall that results from radiation damage. The work reported is in support of the materials surveillance program that will be implemented in conjunction with the upgrade design. Modifications to the earlier models have only a small effect on the results at the primary areas of concern in the vessel wall.
\end{abstract}





\section{INTRODUCTION}

This report is a supplement to an earlier analysis ${ }^{1}$ in which the displacements/atom/s (dpa rate) in iron (the major constituent in the vessel wall) that result from neutron and gamma radiation were calculated for the High Flux Isotope Reactor (HFIR) pressure vessel. The intent of this report is to document details on an updated calculational model that includes the addition of surveillance specimen mounts (also referred to as carousels). These calculations are required in order to determine the effects from planned enlargement and other design changes to the HB-2 and HB-4 beam tubes. These changes will increase the dpa rates in the vessel and therefore accelerate the embrittlement of the reactor vessel wall at crucial locations. Loss of integrity of the vessel wall as a result of radiation damage has long been an issue of concern. An assessment of vessel integrity for the upgrade design is included in Reference 2. The work reported herein is in support of the materials surveillance program that will be implemented in conjunction with the upgrade design. ${ }^{3}$ This report does not describe the surveillance program, nor does it repeat results presented in Reference 3.

Earlier calculations of dpa rates were performed using models based on the discrete ordinates methodology and utilizing codes from the Oak Ridge National Laboratory (ORNL) DOORS ${ }^{4}$ code system. The current calculations reported herein are nearly identical with the exception that new designs for specimen mounts are incorporated into the models. In some cases the spatial boundaries have been changed somewhat to accommodate the specimen mounts. These modifications have a small effect on the results at the primary areas of concern in the vessel wall, i.e. the beam tube nozzle areas. 



\section{UPDATED BEAM TUBE MODELS}

\subsection{General Remarks}

Figures 1 through 5 show modified models for beam tubes HB-1 and HB-4, (present design), HB-2 (present design, unmodified model), HB-2 (new design), HB-3, and HB-4 (new design). Figure 1 includes an index of the numerically designated regions. These region numbers are the same for the remaining figures; therefore, the index is not repeated on Figures 2 through 4 . The same coordinate axis naming convention is applied to the figure plots as was described in Reference 1 . In this convention, the $\mathrm{X}$ axis is oriented along the long axis of the beam tube and the $\mathrm{Z}$ axis (not shown) is in the vertical direction of the reactor core. The plots are shown in the reactor midplane with the beamtube axis $(\mathrm{X})$ running from bottom to top on the plot. Thus, the $\mathrm{Z}$ axis projects outward from the plot toward the viewer. For the two-dimensional plots of HB-2, the radial axis is labeled as $-\mathrm{Y}$ for consistency with this convention.

The model for HB-2 (present design), shown in Figure 2, has not been changed and is shown here for convenience. Models for HB-2 (new design), HB-1 and HB-4 (present design), HB-3, and HB-4 (new design), shown in Figures 1, 3, 4, and 5, all show the addition of specimen mounts. The reader is referred to Reference 3 for drawings and descriptions of the actual mounts and to Appendix A of Reference 3 for a complete set of iso-plots. Appendix A of this report shows sample iso-plots for these models. 


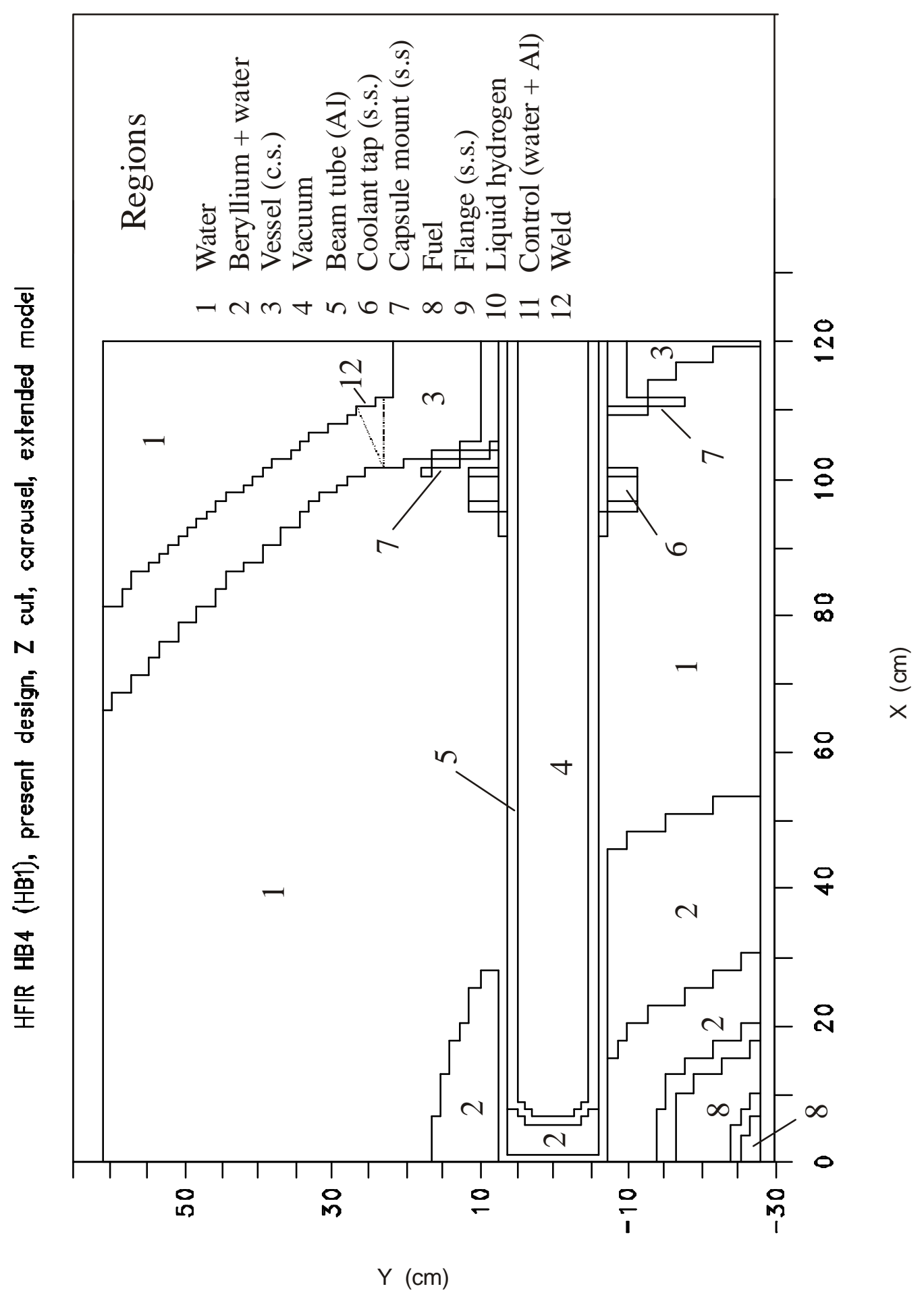

Figure 1. Geometry/material model for HB-1 and HB-4 (present design; HB-4 shown; HB-1 is mirror image) with specimen mount included. 


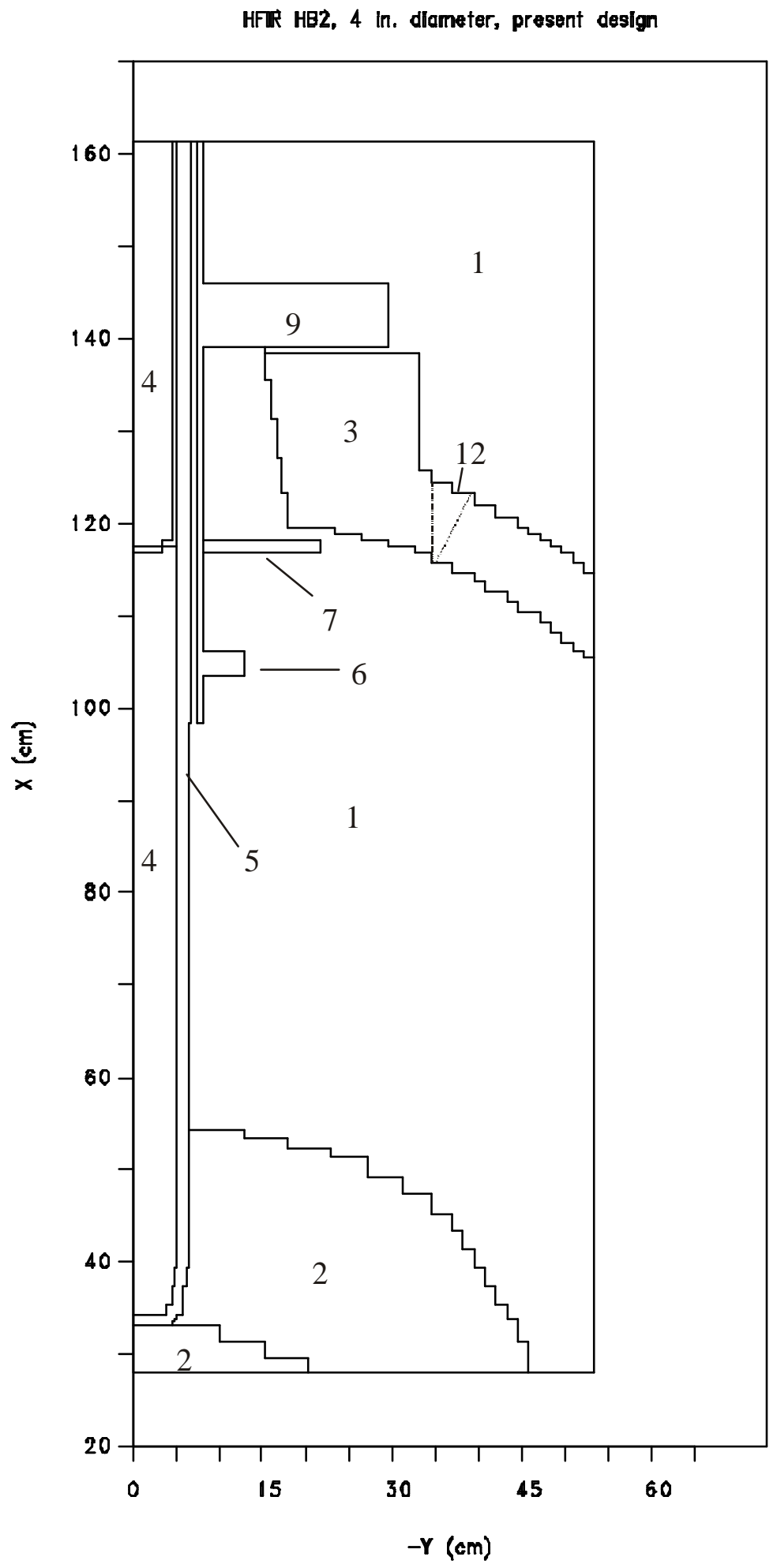

Figure 2. Geometry/material model for HB-2 (present design). 
HFIR HE2, 9 in. dia, modifled design w/ corousel (rov)

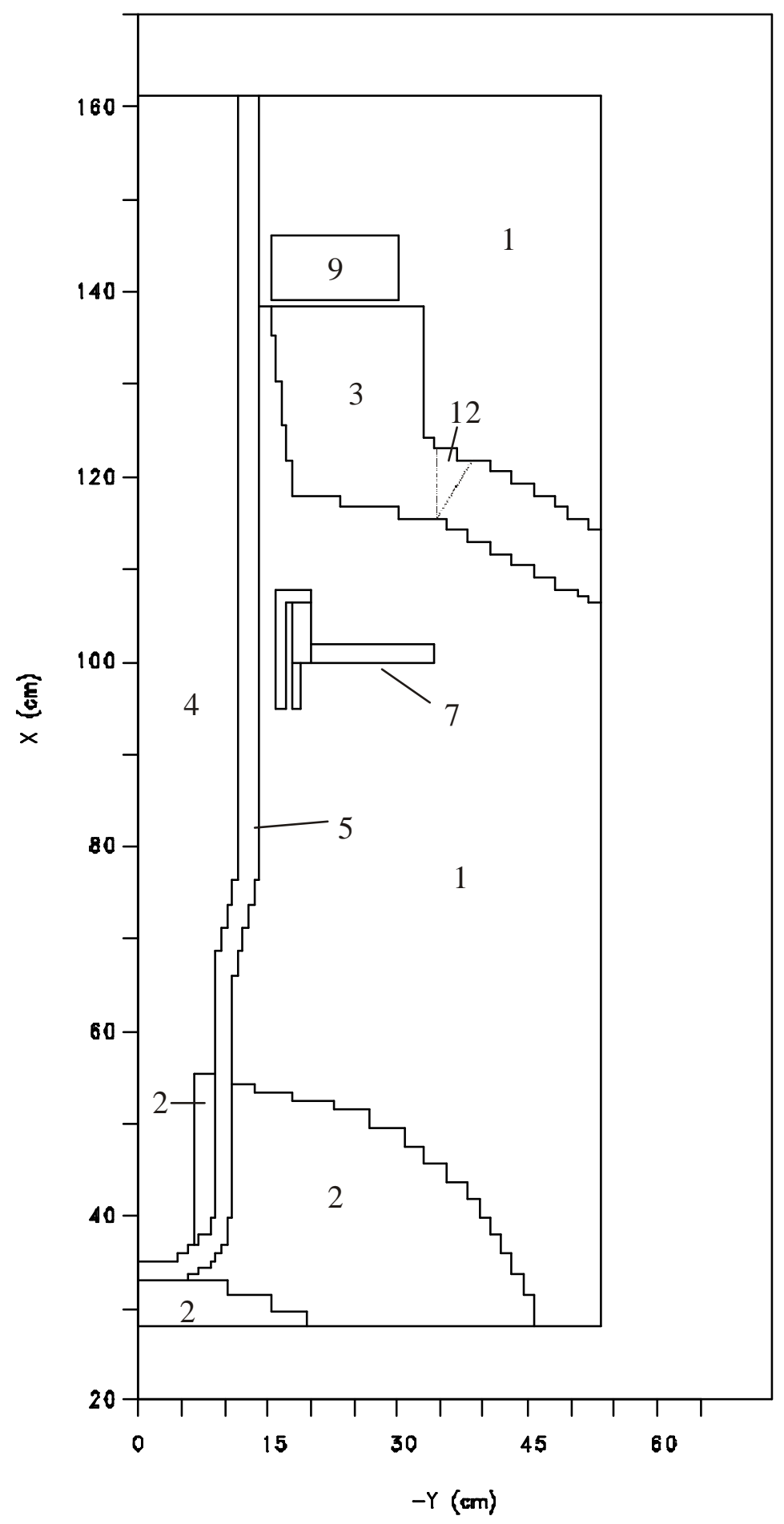

Figure 3. Geometry/material model for HB-2 (new design) with specimen mount included. 


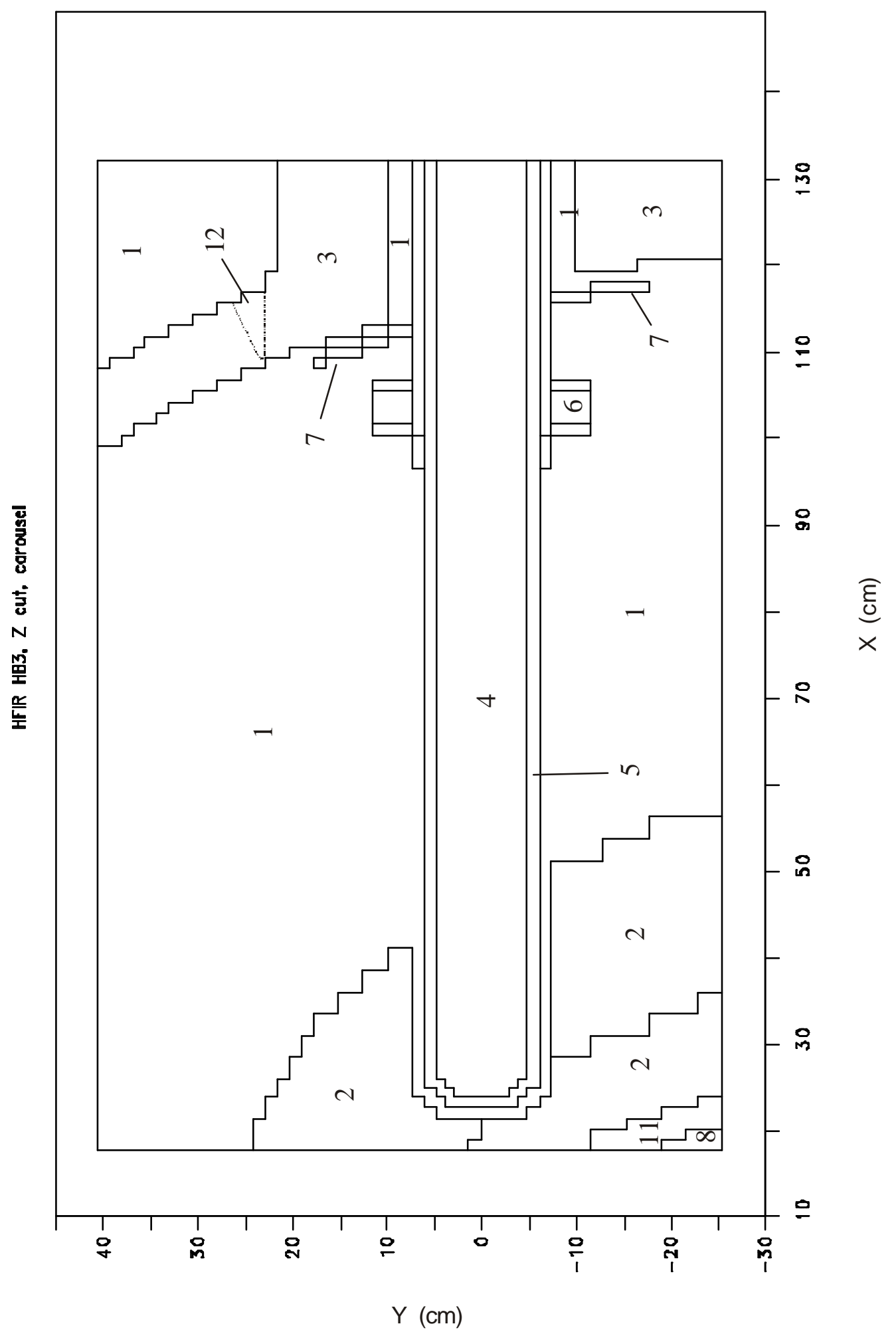

Figure 4. Geometry/material model for HB-3 with specimen mount included. 


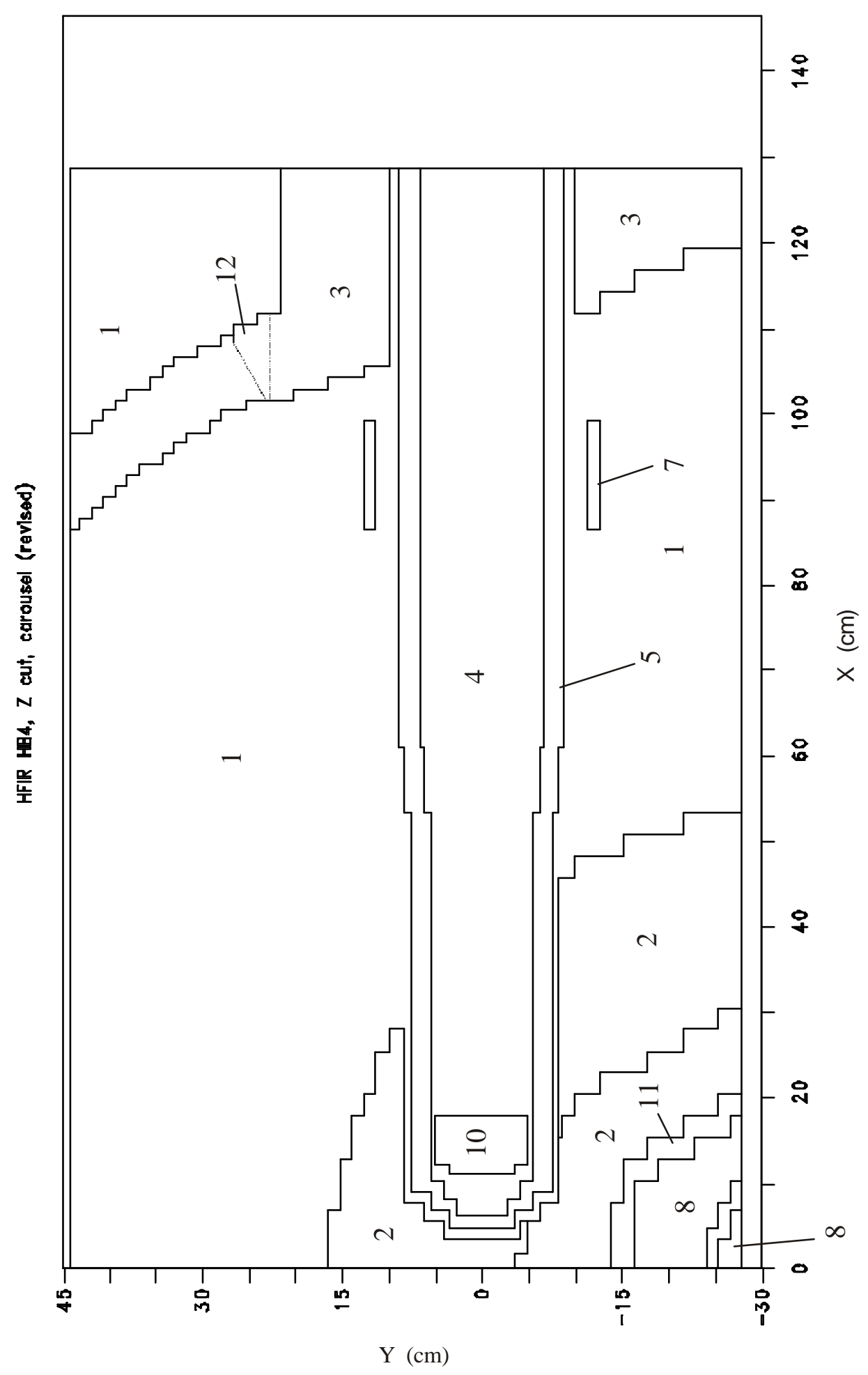

Figure 5. Geometry/material model for HB-4 (new design) with specimen mount included. 


\subsection{Updated Model for HB-1 (HB-4, Present Design)}

The updated model for HB-1 (HB-4, present design), shown in Figure 1, shows three modifications from the original model. ${ }^{1}$ A specimen mount has been added, the model has been extended $16.8 \mathrm{~cm}$ in the $+Y$ dimension from $44.2 \mathrm{~cm}$ to $60.96 \mathrm{~cm}$ to include Key 6 and 7 locations, and the model has been reduced in the $\mathrm{X}$ dimension from 128.5 $\mathrm{cm}$ to $120.1 \mathrm{~cm}$. The last change was made so that the boundaries of the model would not fall outside of the fixed source core model, which provides the boundary source for the beam tube model. The specimen mount is approximated by nine right parallelepipeds (RPPs) simulating a stainless steel circular plate parallel with the vessel wall. Although only the XY plane at the core midplane is shown in figure 1, the RPPs are varied in height in the $\mathrm{Z}$ dimension to simulate a circular configuration. The mount has a thickness of $1.27 \mathrm{~cm}(0.5 \mathrm{in}$.) and is located $1.27 \mathrm{~cm}(0.5 \mathrm{in}$.) from the vessel wall in the $\mathrm{X}$ dimension.

\subsection{Updated Model for HB-2 New Design}

The updated model for HB-2, new design, shown in Figure 3, includes a simplified specimen holder shown in detail in Reference 3. Figure 6 gives a more detailed drawing of the specimen holder section of the model showing dimensions and materials. In order to simplify the design for a discrete ordinates representation, materials in the specimen regions, labeled " $2 \mathrm{C}$ " and " $2 \mathrm{~W}$ " (core and weld; see Ref. 3), are represented as mixtures of stainless steel and water. Because HB-2 was modeled in two-dimensions, the holder has rotational symmetry about the beam tube axis; therefore both regions are modeled appropriately as annuli.

\subsection{Updated Model for HB-3 Present Design}

The updated model for the present design of HB-2, shown in Figure 4, includes a stainless steel specimen mount similar to that modeled for HB-1 and discussed previously. The specimen mount is approximated in a similar way by eight RPPs which vary in height ( $+Z$ dimension) to approximate a circular configuration approximately parallel to the vessel wall. The mount is $1.27 \mathrm{~cm}(0.5$ in.) thick and is located $1.27 \mathrm{~cm}$ (0.5 in.) from the vessel wall.

\subsection{Updated Model for HB-4 New Design}

The updated model for the new design of HB-4 is shown in Figure 5. The specimen mount in this model is a simple stainless steel annulus with inner and outer radii of 11.43 $\mathrm{cm}$ (4.5 in.) and $12.7 \mathrm{~cm}(5 \mathrm{in}$.) respectively. Thus, the thickness of the annulus is 1.27 $\mathrm{cm}(0.5 \mathrm{in}$.). The annulus is simulated by six RPPs that vary in height ( $+\mathrm{Z}$ dimension) and location in order to approximate a cylindrical shape around the beam tube. The length of the annulus is $12.7 \mathrm{~cm}(5 \mathrm{in}$.) and its starting position along the $\mathrm{X}$-axis is at 86.4 $\mathrm{cm}$. 


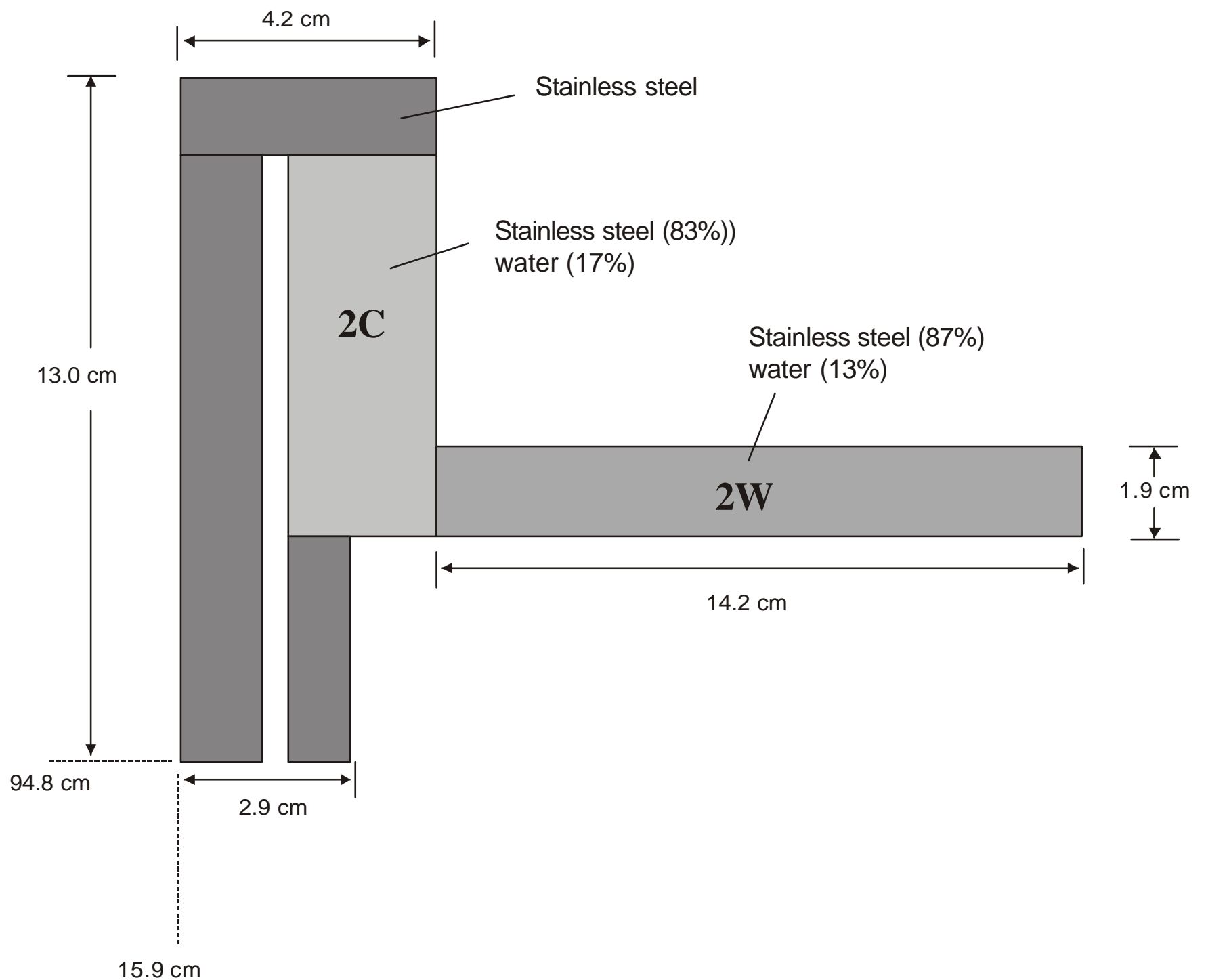

Figure 6. Detail of model implementation of specimen mount for HB-2(new design). 


\section{DATA/CODE ARCHIVE}

Files for the updated and earlier models have been archived and can be made available as necessary. In addition, code output, data files, and the software package have also been retained. Appendix D of Reference 1 describes the archive and gives additional explanation for reproducing the results. Appendix B of this report describes additional archive information relating to the revised calculations reported herein. 



\section{SUMMARY}

This report is a supplement to Reference 1; it describes revisions to existing HFIR beam tube models developed originally in conjunction with the HFIR vessel life extension program. ${ }^{2}$ The revisions to the models have been made primarily to include approximations to specimen mounts that will contain samples to be irradiated as part of the materials surveillance program ${ }^{3}$ following the HFIR upgrade. Comprehensive results from these calculations for crucial areas of the vessel (nozzle corner, weld) and the specimen locations (keys) are reported in Reference 3. 



\section{REFERENCES}

1. E. D. Blakeman, Neutron and Gamma Fluxes and dpa Rates for the HFIR Vessel Beltline Region (Present and Upgrade designs), ORNL/TM-13693, Oak Ridge National Laboratory, November 2000.

2. R. D. Cheverton, HFIR Vessel Life Extension with Enlarged HB-2 and HB-4 Beam Tubes, ORNL/TM-13698, December 1998.

3. R. D. Cheverton, R. K. Nanstad, and E. D. Blakeman, HFIR Pressure Vessel and Structural Components Materials Surveillance Program, Supplement 2, ORNL/TM1372/S2, August 1999.

4. DOORS3.1, RSICC Computer Code Collection, CCC-650, Radiation Safety information Computational Center, Oak Ridge National Laboratory, (1996). 



\section{APPENDIX A}

\section{SAMPLE UPDATED ISO-PLOTS}





\section{APPENDIX A \\ SAMPLE UPDATED ISO-PLOTS}

Figures A1 through A4 show sample normalized iso-plots ${ }^{*}$ of the total dpa rate for the following beam tubes: HB-1 (HB-4, present design), HB-2 (new design), HB-3, and HB4 (new design). Model changes were not implemented for HB-2, present design; therefore, no additional updated iso-plots are shown for that design. These iso-plots are identical to those shown in Appendix A of Reference 3. The reader is directed to this document for a more complete iso-plot display of data including separate neutron and gamma iso-dpa rate and fluxes. The same normalization factors as determined in Reference 1 are used for each case.

\footnotetext{
* The prefix "iso-" is used to refer to equivalue contour lines in these plots and is used with the quantity of interest in some cases, e.g., iso-dpa rate and iso-flux. Also, in labels on these plots, the symbol "•" is placed over the letters "dpa" to indicate dpa rate as in earlier reports.
} 


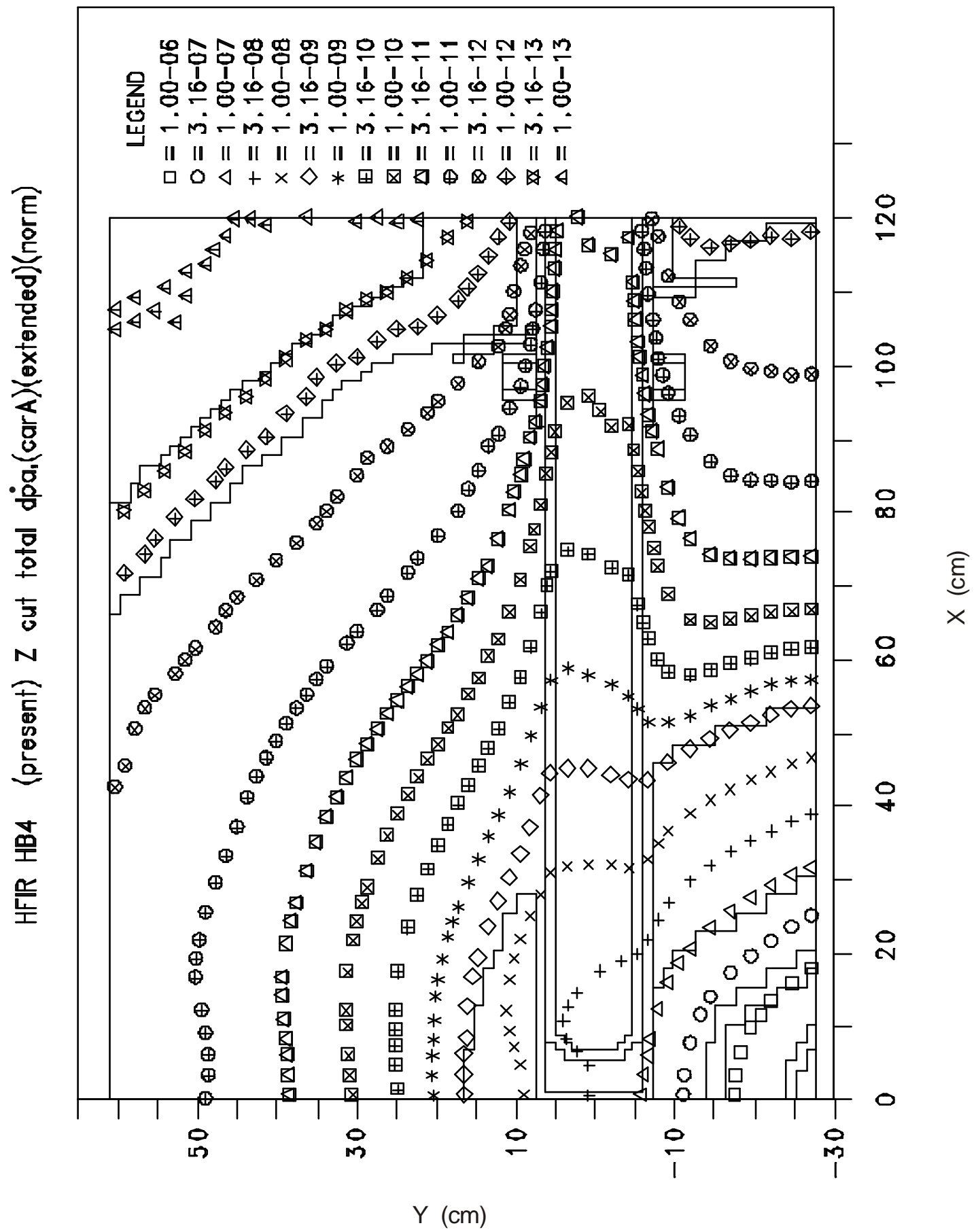

Figure A1. Total (neutron + gamma) iso-dpa rate (displacements/atom/s) for HB-1 and HB-4 (present design; HB-4 shown; HB-1 is mirror image) with specimen mount included. 
HFIR hb2 9 In., $100 \mathrm{MW}, 84 \mathrm{gp}$, total dpa, rev 2 car. (norm)

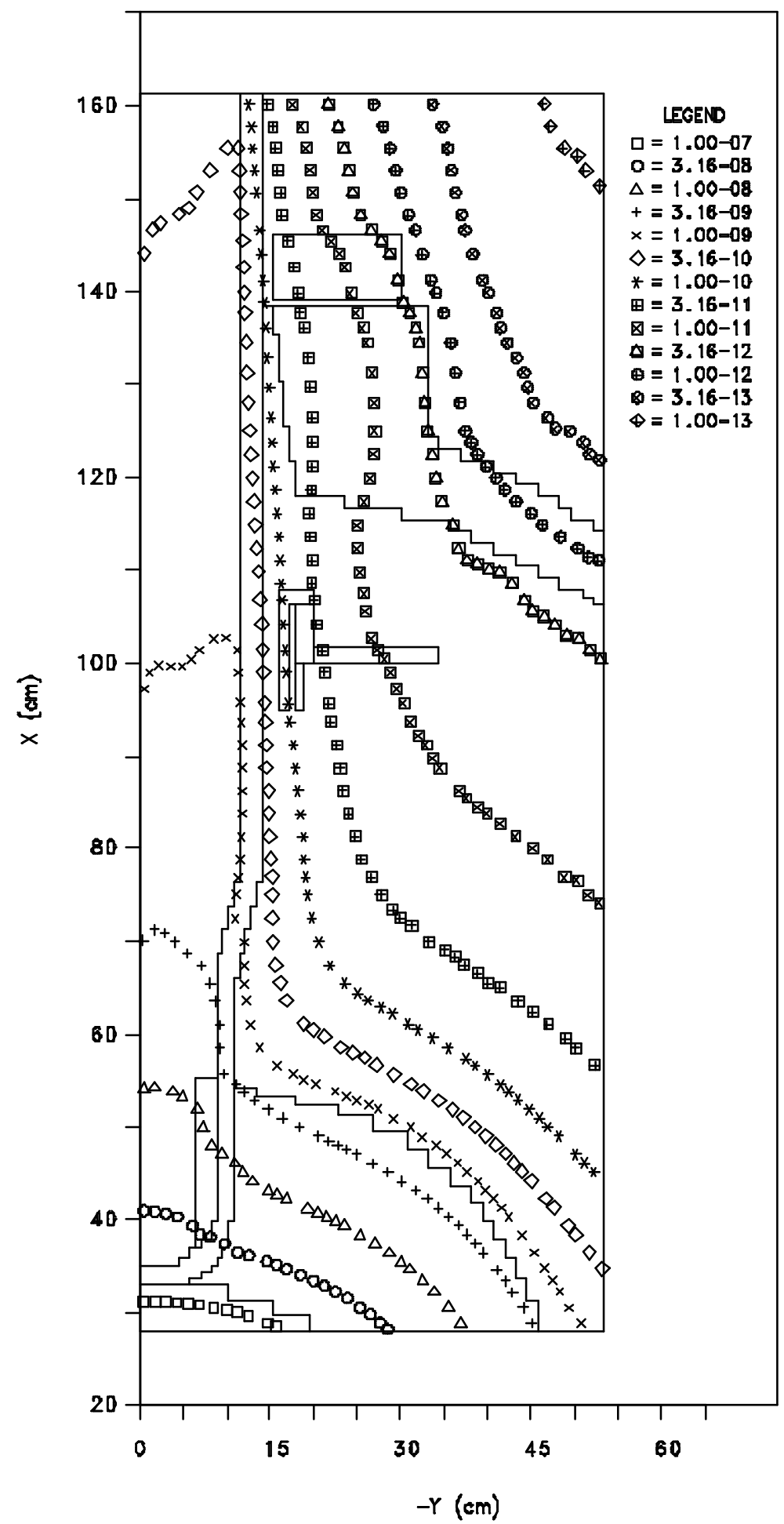

Figure A2. Total (neutron + gamma) iso-dpa rate (displacements/atom/s) for HB-2 (new design) with specimen mount included 


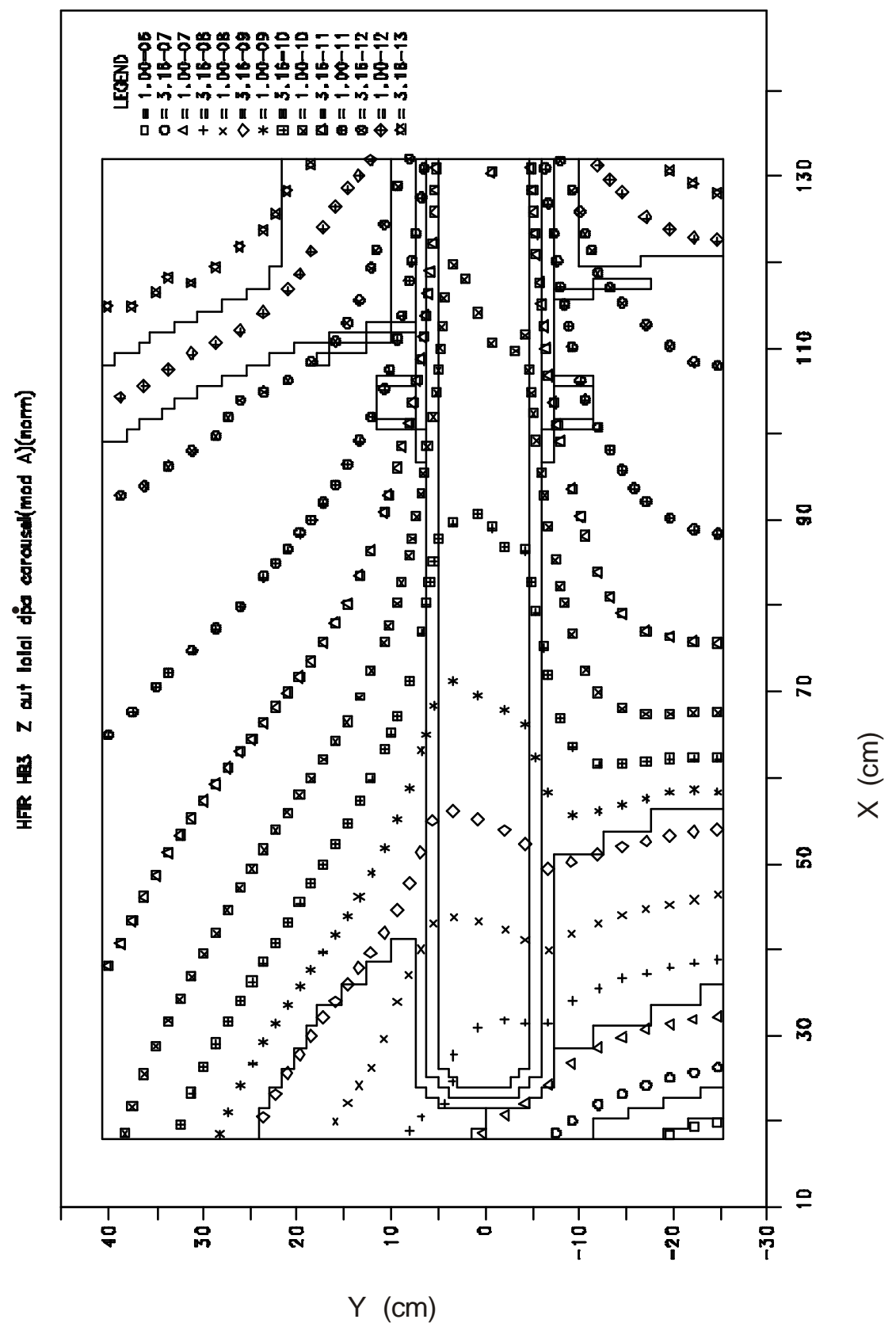

Figure A3. Total (neutron + gamma) iso-dpa rate (displacements/atom/s) for HB-3 with specimen mount included. 


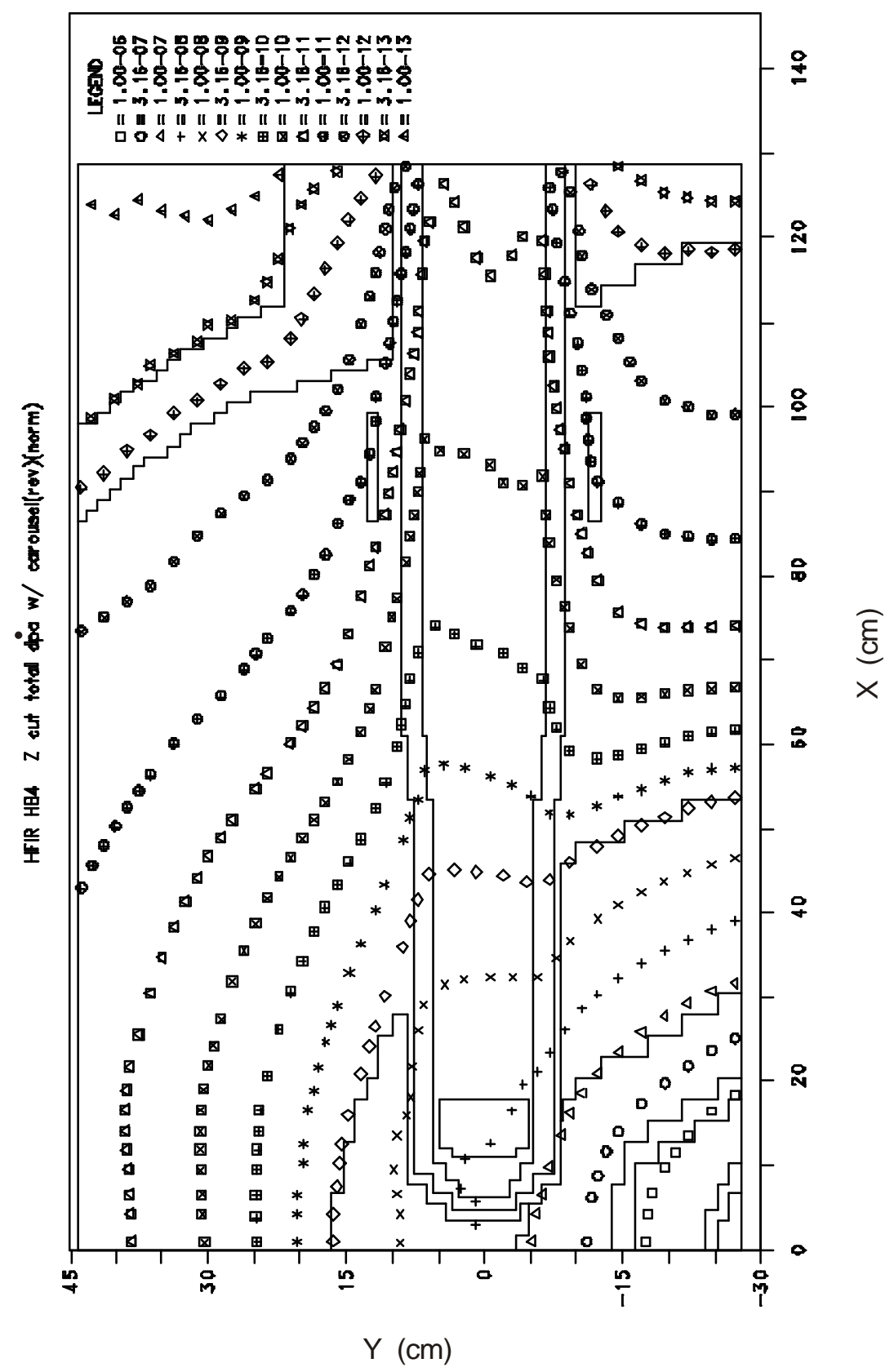

Figure A4. Total (neutron + gamma) iso-dpa rate (displacements/atom/s) for HB-4 (new design) with specimen mount included. 



\section{APPENDIX B}

\section{GUIDE TO CALCULATION MODELS FOR HFIR BEAM TUBES AND DATA ARCHIVAL STORAGE, SUPPLEMENTAL INFORMATION}





\section{APPENDIX B}

\section{GUIDE TO CALCULATION MODELS FOR HFIR BEAM TUBES AND DATA ARCHIVAL STORAGE, SUPPLEMENTAL INFORMATION}

Tables 1 and 2 present supplemental archive information relating to calculations discussed in this report. Reference 1 provides additional explanatory information.

Table B1. Explanation of additional filename terms

\begin{tabular}{|l|l|}
\hline Term & \multicolumn{1}{c|}{ Description } \\
\hline car & DORT and TORT models that include a specimen carousel . \\
\hline CarA & Modified carousel model for HB3 and HB4 \\
\hline CarRev & $\begin{array}{l}\text { Revised carousel model for HB2, 9 in. diameter model } \\
\text { Note: original model contained a carousel design }\end{array}$ \\
\hline carRev2 & $2^{\text {nd }}$ revised carousel model for HB2, 9 in. diameter model \\
\hline Extended & $\begin{array}{l}\text { TORT and associated models for HB4. Extended in +y } \\
\text { dimension to include all of Keys } 6 \text { and 7. Shortened in } \mathrm{x} \\
\text { dimension to avoid running a new fixed source problem. }\end{array}$ \\
\hline
\end{tabular}

Table B2. List of additional DORT/TORT code inputs by beam tube design

\begin{tabular}{|l|l|l|l|}
\hline HB\# & Des & DORT/TORT code file(s) & Comments \\
\hline 2 & $\mathrm{~N}$ & $\begin{array}{l}\text { hfr84hb29.v2.carRev2.sh1 } \\
\text { hfr84hb29.dg.v2.carRev2.sh1 }\end{array}$ & $\begin{array}{l}\text { W/ specimen carrier, latest } \\
\text { revision }\end{array}$ \\
\hline 2 & $\mathrm{~N}$ & $\begin{array}{l}\text { hfr84hb29.v2.carRev2.boc.sh1 } \\
\text { hfr84hb29.dg.v2.carRev2.boc.sh1 }\end{array}$ & $\begin{array}{l}\text { BOC conditions w/ specimen } \\
\text { carrier }\end{array}$ \\
\hline $1(4)$ & $\mathrm{P}$ & $\begin{array}{l}\text { tort.new.hb4.fs.highz.v2.carA.sh1 } \\
\text { tort.new.hb4.fs.dg.highz.v2.carA.sh1 }\end{array}$ & $\begin{array}{l}\text { W/ specimen carrier, latest } \\
\text { revision }\end{array}$ \\
\hline $1(4)$ & $\mathrm{P}$ & $\begin{array}{l}\text { tort.new.hb4.fs.highz.v2.carA.extended.sh1 } \\
\text { tort.new.hb4.fs.dg.highz.v2.carA.extended.sh1 }\end{array}$ & $\begin{array}{l}\text { Model extended to include seam } \\
\text { weld }\end{array}$ \\
\hline 4 & $\mathrm{~N}$ & $\begin{array}{l}\text { tort.mod.hb4.fs.highz.v2.car.rev.sh1 } \\
\text { tort.mod.hb4.fs.dg.highz.v2.car.rev.sh1 }\end{array}$ & $\begin{array}{l}\text { W/ specimen carrier, latest } \\
\text { revision }\end{array}$ \\
\hline 3 & $\mathrm{P}$ & $\begin{array}{l}\text { tort.new1.hb3.fs.v2.carA.sh1 } \\
\text { tort.new1.hb3.fs.dg.v2.carA.sh1 }\end{array}$ & $\begin{array}{l}\text { W/ specimen carrier, latest } \\
\text { revision }\end{array}$ \\
\hline
\end{tabular}

Notes:

1) script in the codes contain names of flux/response files. Comments contain explanations for the use of the code. Also, see glossary of terms.

2) $\mathrm{P}=$ present, $\mathrm{N}=$ new under Des (Design) column.

3) files come in pairs because of separate delayed gamma run. 



\section{INTERNAL DISTRIBUTION}

1-5. E. D. Blakeman

6. W. K. Brown

7. J. A. Bucholz

8. S. E. Burnette

9. S. J. Chang

10. R. D. Cheverton

11. D. H. Cook

12. R. E. Daniels

13. T. L. Dickson

14. H. R. Fair

15. M. B. Farrar

16. G. F. Flanagan

17. M. L. Gildner

18. R. E. Hale

19. R. M. Harrington

20. R. W. Hobbs

21. J. R. Inger

22. D. T. Ingersoll

23. S. K. Iskander

24. M. W. Kohring
25. M. A. Kuliasha

26. J. E. Lee

27. R. A. Lillie

28. M. A. Linn

29. R. S. McKeehan

30. L. D. Merryman

31. R. H. Morris

32. J. V. Pace III

33. L. D. Proctor

34. I. Remec

35. J. B. Roberto

36. R. B. Rothrock

37. C. O. Slater

38. R. M. Stinnett

39-40. RRD-DCC

41. Central Research Library

42. Laboratory Records-RC

43. Laboratory Records

(for submission to OSTI) 
